\title{
Literatura surda na região amazônica: o ambiente educacional como espaço da construção da identidade a partir da experiência estética
}

\author{
Deaf literature in the Amazon region: the
} educational environment as a space for the construction of identity from aesthetic experience

\author{
Literatura sorda en la región amazónica: el \\ ambiente educativo como espacio de la construcción \\ de la identidad a partir de la experiencia estética
}

\author{
Nerli Nonato Ribeiro Mori ${ }^{1}$ \\ Larissa Gotti Pissinatti
}

DOI: http://dx.doi.org/10.20435/serie-estudos.v0i0.1254

\begin{abstract}
Resumo: O presente artigo objetiva apresentar uma revisão de literatura das produções denominadas de literatura surda na/da Amazônia. Essas produções recontam narrativas locais adaptando-as para o contexto linguístico-cultural dos surdos. A escola é o espaço privilegiado de contato com essas narrativas, possibilitando aos surdos o desenvolvimento de aspectos constituidores de sua identidade. Para tanto, dividimos este trabalho em três momentos. No primeiro, situamos as produções literárias do povo surdo pelo viés da experiência estética, situada no contexto cultural regional, fundamentando-nos em Compagnon (2012) e Loureiro (2002). No segundo momento, discutimos a possibilidade da literatura como instrumento para a experiência estética e, por fim, aprofundaremos, a partir de Lev S. Vigotski e Yves Lenoir, a escola como espaço mediador da experiência estética, da identificação e do desenvolvimento dos valores linguísticoculturais dos surdos. Os resultados confirmam a literatura surda amazônica como instrumento para a formação da identidade dos surdos presentes na região da Amazônia Legal.
\end{abstract}

Palavras-chave: literatura surda; experiência estética; mediação; identidade.

Abstract: The present article aims to present a literature review of the productions called deaf literature in/from the Amazon. These productions recount local narratives adapting them to the cultural-linguistic context of the deaf. The school is the privileged space of contact with these

\footnotetext{
${ }^{1}$ Universidade Estadual de Maringá (UEM), Maringá, Paraná, Brasil.

${ }^{2}$ Universidade Federal de Rondônia (UNIR), Porto Velho, Rondônia, Brasil.
} 
narratives, enabling the deaf to develop aspects that constitute their identity. To do so, we divided this work into three moments. In the first, we will situate the literary productions of the deaf people through the bias of aesthetic experience, situated in the regional cultural context, based on Compagnon (2012) and Loureiro (2002). In the second moment, we discuss the possibility of literature as an instrument for aesthetic experience, and, finally, from Lev S. Vygotsky and Yves Lenoir, we examine the school as a mediating space for aesthetic experience, identification and development of linguistic-cultural values of deaf people. The results confirm the Amazonian deaf literature as an instrument for the identity formation of deaf people present in the Legal Amazon region.

Keywords: deaf literature; aesthetic experience; mediation; identity.

Resumen: El presente artículo tiene por objeto presentar una revisión de literatura de las producciones denominadas de literatura sorda en la Amazonia. Esas producciones recogen narrativas locales adaptándolas al contexto lingüístico-cultural de los sordos. La escuela es el espacio privilegiado de contacto con esas narrativas, posibilitando a los sordos el desarrollo de aspectos constitutivos de su identidad. Para ello, dividimos ese trabajo en tres momentos. En el primero, situaremos las producciones literarias del pueblo surdo por el sesgo de la experiencia estética, situada en el contexto cultural regional, basándonos en Compagnon (2012) y Loureiro (2002). En el segundo momento, discutimos la posibilidad de la literatura como instrumento para la experiencia estética y, finalmente, profundizamos, a partir de Lev S. Vygotsky y Yves Lenoir, la escuela como espacio mediador de la experiencia estética, identificación y desarrollo de los valores lingüístico-culturales de los sordos. Los resultados confirman la literatura sorda amazónica como instrumento para la formación de la identidad de los sordos presentes en la región de la Amazonia Legal.

Palabras clave: literatura sorda; experiencia estética; mediación; identidad.

\section{INTRODUÇÃO}

Este artigo pretende fazer uma revisão de literatura sobre a formação da identidade dos surdos na região amazônica, a partir da literatura surda produzida na região. Entendemos a escola e o professor como um "instrumento mediador" (VIGOTSKI, 2000), para a experiência estética com a literatura surda da região amazônica. Nesse processo, o trabalho do professor é fundamental para que o surdo tenha a formação e o desenvolvimento de sua identidade, considerando suas especificidades linguístico-culturais e as especificidades culturais da região amazônica, que compreendemos como a região considerada legal, abrangendo grande parte do norte, parte do centro-oeste e do nordeste do Brasil.

Na primeira parte do artigo, abordamos aspectos contextuais que situam a literatura surda como produção regional, assim como aproximamos as características da literatura surda e da literatura regional embasando os argumentos em 
Literatura surda na região amazônica: o ambiente educacional como espaço da construção da identidade a partir da experiência estética

pesquisadores da literatura surda como Karnopp (2006), Holcomb (2013), Mourão (2011), Strobel (2013) e Loureiro (2002), pesquisador da literatura produzida da/ na Amazônia.

Na segunda parte, tratamos da literatura surda como possiblidade de experiência estética a partir dos argumentos de Compagnon (2012) e Loureiro (2002). E na terceira parte discutimos, a partir da concepção de mediação em Lev S. Vigotski e Yves Lenoir, a noção de mediação e a importância da literatura na construção da identidade do sujeito surdo.

Para discutir os aspectos regionais, apresentamos as capas das obras produzidas pela comunidade surda da região amazônica. Quando nos referimos à comunidade surda, entendemos sujeitos que participam politicamente das conquistas e lutas dos surdos, portanto, professores, familiares, intérpretes, amigos e outros profissionais que de uma forma ou de outra estão em contato com esses sujeitos.

Encontramos três obras produzidas na região, são elas: Negrinho e Solimões (MONTEIRO, 2014), Onze história e um segredo: desvendando as lendas amazônicas (SALES, 2016) e Curupira surdo (ESPÍNDOLA; SILVA; PISSINATTI, 2016). Essas narrativas tratam de adaptações de mitos da região, em que as personagens protagonistas se apresentam como surdas e utilizam a língua de sinais.

Em todas as narrativas há uma perspectiva positiva em ser surdo e ênfase em seus valores linguístico-culturais. Além disso, outra característica marcante são as paisagens, tipicamente regionais, evidenciadas nas ilustrações das obras. Por uma questão de tempo, apresentaremos as capas, para que o leitor observe as evidências de aspectos da região amazônica que são representados nas obras.

$\mathrm{Na}$ terceira parte do artigo, discutimos a noção de mediação a partir de Vigotski e Yves Lenoir, aprofundando também os aspectos metodológicos do trabalho com a literatura surda. Para esses autores, a escola é o espaço privilegiado, assim como o trabalho do professor, como interventor primeiro, a possibilitar um espaço profícuo para uma experiência estética, em que o aluno surdo possa encontrar-se consigo mesmo e com o outro a partir da literatura surda, desenvolvendo, assim, sua identidade. 


\section{LITERATURA SURDA E EXPERIÊNCIAS VISUAIS NA AMAZÔNIA}

Os surdos constituem uma comunidade linguística, reconhecida no Brasil pela Lei 10.436/2002. O reconhecimento da língua brasileira de sinais (Libras) contribuiu para o fomento de publicações dessa comunidade. Na década de 1990, surgiram as primeiras obras. O conjunto das obras produzidas na comunidade surda é denominado de literatura surda.

Para Mourão (2011), não há um conceito definidor de literatura surda, isso porque se trata de um fenômeno recente e em construção. Conforme Holcomb (2013), Karnopp (2006) e Mourão (2011), a literatura surda se caracteriza por evidenciar as vivências e experiências dos surdos. São experiências positivas em relação à sua condição e apresentam os valores linguístico-culturais dos surdos. Segundo Karnopp (2006, p. 102), a literatura surda são histórias que têm a língua de sinais, a questão da identidade e da cultura surda presentes na narrativa. Literatura surda é a produção de textos literários em sinais, que entende a surdez como presença de algo, e não como falta, possibilitando outras representações de surdos, considerando-os como um grupo linguístico e cultural diferente.

A diferença linguística dos surdos, o uso da língua de sinais, é uma marca presente nas produções dessa comunidade. Conforme Strobel (2013), a literatura surda constitui um artefato cultural dos surdos e por artefato se compreende "[...] tudo o que se vê e sente quando está em contato com a cultura de uma comunidade como material, vestuário, maneira como se dirige ao outro, tradições, valores, normas, etc." (STROBEL, 2013, p. 43). Essa perspectiva de compreensão das narrativas, como um construto cultural vem ao encontro da noção de cultura em Vigotski (1969), em seu texto "Psicologia concreta do homem". Nesse texto, o autor apresenta uma discussão do conceito de cultura, aproximando-a da história. Isso porque, para Vigotski, a cultura é um processo recorrente da relação com os outros.

A relação com o outro é externalizada de forma simbólica, seja pela língua, seja pela maneira de agir, pensar e criar. Os significados são externalizados e "[...] transferidos para a personalidade, relações interiorizadas de ordem social, base da estrutura social da personalidade" (VIGOTSKI, 2000, p. 26). Com isso, queremos dizer que, ao produzir um artefato, como a literatura, o sujeito externaliza os significados construídos na sua relação com o outro e desenvolve sua identidade, assim como contribui no desenvolvimento da identidade de um determinado grupo social ao qual pertence. 
Literatura surda na região amazônica: o ambiente educacional como espaço da construção da identidade a partir da experiência estética

Compreendemos, neste trabalho, a identidade como uma marca produzida por meio da construção de significados, com os quais o sujeito se identifica por meio das relações e trocas culturais; por isso dizer que, ao evidenciar sua identidade, o sujeito também determina seu local de fala, posicionando-se com sua diferença em meio às diferenças (WOORDWARD, 2012). Dessa forma, a identidade é um processo de identificação e apresentação de si, de seus aspectos culturais por meio de representações.

A literatura surda é uma forma de os surdos representarem a si mesmos, suas vivências e experiências, enquanto parte de um construto cultural desenvolve e apresenta significados obtidos nas relações sociais.

[...] a representação inclui práticas de significação e os sistemas simbólicos por meio dos quais os significados são produzidos, posicionando-nos como sujeito. É por meio dos significados produzidos pelas representações que damos sentido à nossa experiência e àquilo que somos. Podemos inclusive sugerir que esses sistemas simbólicos tornam possível aquilo que somos e aquilo no qual podemos nos tornar. (WOORDWARD, 2012, p. 17-8).

Assim, podemos aferir que, nas representações da literatura surda, há um espaço de significados produzidos no qual as experiências e vivências são marcadas pelos aspectos culturais locais que também fazem parte de um construto não somente individual, mas também coletivo. Segundo Woordward (2012, p. 18),

A representação, compreendida como um processo cultural, estabelece identidades individuais e coletivas e os sistemas simbólicos nos quais ela se baseia fornecem possíveis respostas às questões: Quem sou? O que eu poderia ser? Quem eu quero ser? Os discursos e os sistemas de representação constroem os lugares a partir dos quais os indivíduos podem se posicionar e a partir dos quais podem falar.

Nesse contexto, confirmamos a ideia de que a literatura surda da região amazônica é o construto cultural e regional, ou seja, há uma literatura surda amazônica que tem traços específicos de uma cultura particular, em que os significados são constituídos de maneira diferente de outras regiões do país.

Segundo Loureiro (2002, p. 140), “a cultura regional é sempre entendida como ligada ao espontâneo, ao primitivo, à festa, à naturalidade e à superficialidade". Assim, com a noção de produção regional, abre-se também para a ideia de uma produção específica, ou seja, há elementos que promovem, por meio da 
literatura surda, um processo de identificação, contribuindo, assim, para fortalecer o sentimento de pertencimento a um grupo linguístico-cultural que faz parte de uma determinada região do Brasil.

\section{EXPERIÊNCIA ESTÉTICA DOS SURDOS NA AMAZÔNIA}

A literatura surda regional a que nos referimos são as produções em que a "cultura amazônica apresenta aspectos regionais onde o homem está integrado à natureza" (LOUREIRO, 2002, p. 122). Nessas produções, é possível observar elementos culturais que são parte da cultura local: rios, animais, floresta, frutos etc. Para Loureiro (2002), o elemento regional, no caso, a cultura amazônica, "não se trata de algo tradicionalista, mas elemento presente no imaginário estético, é expressão histórica" (LOUREIRO, 2002, p. 129). Esses elementos podem ser observados logo na capa das narrativas. Observe as figuras abaixo:

Figura 1 - Adaptações de mitos amazônicos

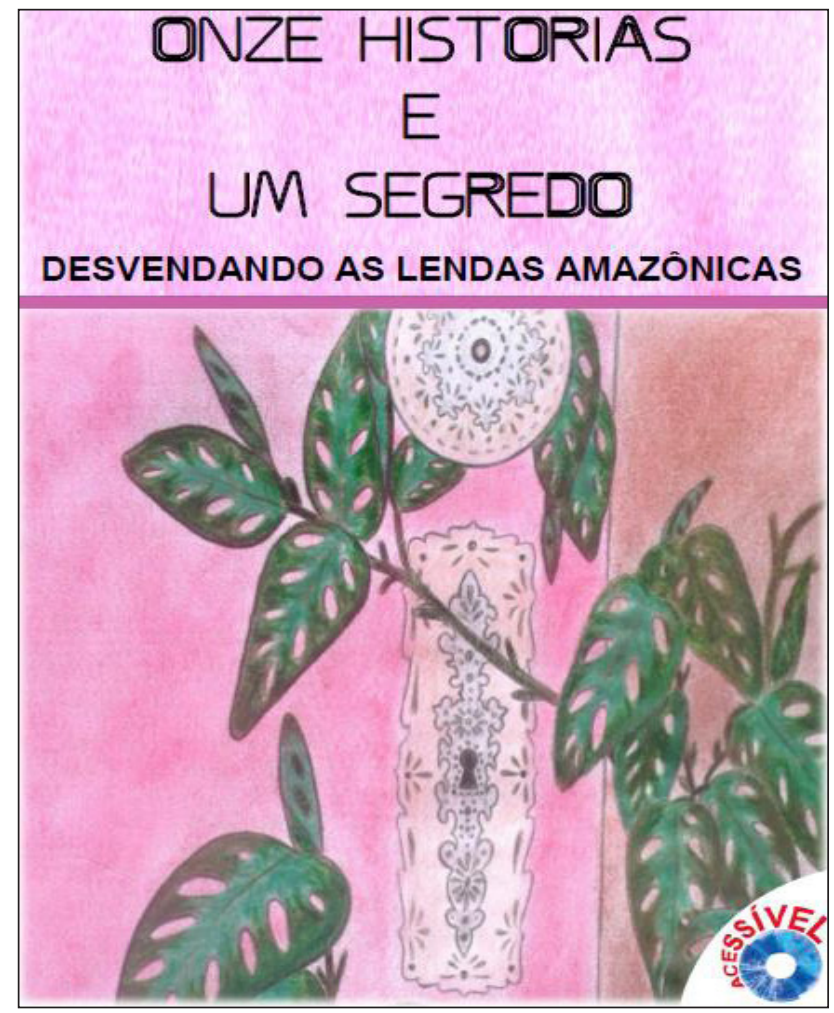

Fonte: Imagem da capa de Sales (2016). 
Figura 2 - Adaptação do mito Rio Negro e Solimões

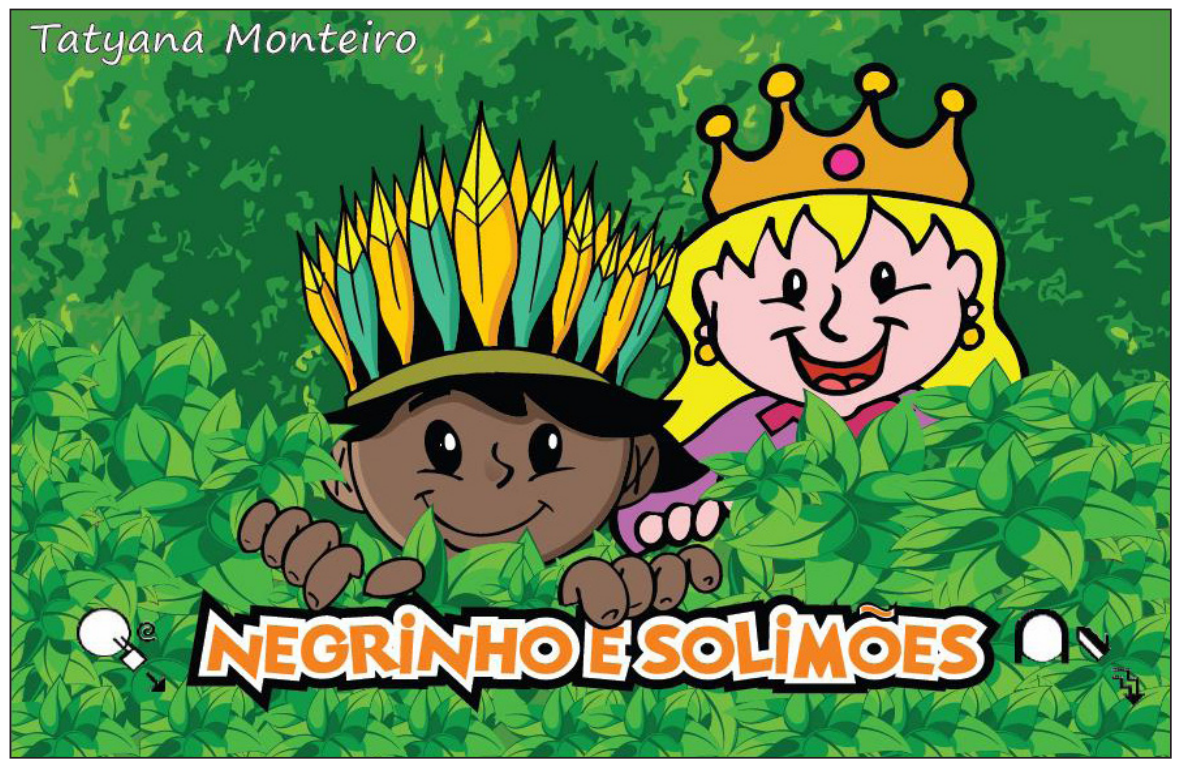

Fonte: Imagem da capa de Monteiro (2014).

Figura 3- Adaptação do mito Curupira

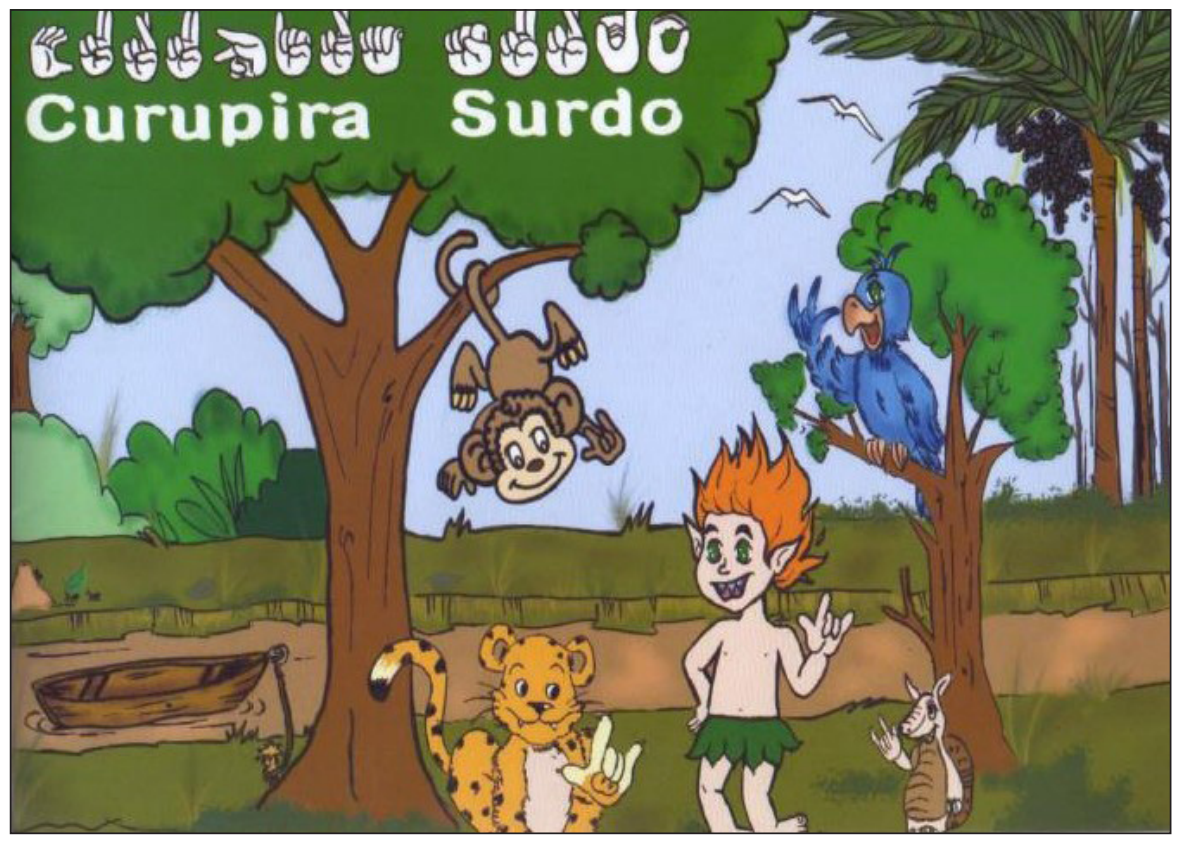

Fonte: Imagem da capa de Espíndola, Silva e Pissinatti (2016). 
Observe que as três produções têm as marcações da cultura regional. Na figura 1, é possível reconhecer a folhagem típica da floresta, e ao centro, traços de desenhos típicos do povo indígena. Já na figura 2 encontramos novamente a floresta, as cores fortes e a personagem indígena contrastando com a personagem de outra cultura. Na figura 3, percebem-se os animais locais, os frutos regionais, como o açaí, o barco e a cor do rio da região. Para Loureiro (2002, p. 133), "a Amazônia tem sua visualidade marcada por grandes linhas de força como a natureza, as tribos indígenas e sua cultura, as manifestações da arte popular, a arte plumária, a cerâmica, as embarcações, as casas, os rios".

Outro elemento que marca a regionalidade dessas produções são as cores, chamando atenção para uma questão que vem ao encontro de um aspecto cultural dos surdos: as experiências visuais.

[...] a visualidade amazônica celebra a glória do olhar. A cor faz-se participante do brilho das coisas. Torna-se uma poética em festa, pois engendra um constante jorrar de signos e emoções. É a vida florescente ao lado da vida natural marcada pela ideia de incompletude. Uma forma de beleza que se realiza no olhar que estranha o mundo. O imprevisível apreendido. O mundo percebido pela cor primordial, e expresso numa forma de distorção das normas estéticas dominantes. Um lírico retorno às fontes do olhar! (LOUREIRO, 2002, p. 138)

A cultura regional, assim como diz Loureiro (2002, p. 138), "ao celebrar a glória do olhar", aproxima as produções da Amazônia com um dos artefatos culturais do povo surdo: as experiências visuais. O olhar é o elemento que promove o estranhamento, a curiosidade; por meio dele, os significados vão sendo construídos. Essa especificidade também é promotora de uma identidade que, conforme Strobel (2013, p. 44), "refere-se ao sentimento de pertencimento a uma cultura, isto é, à interação do sujeito surdo com a sua comunidade". Dessa forma, o que se representa constitui parte de uma identidade cultural tanto linguística - no caso dos surdos, a Libras - como de um campo maior, de relações com a natureza, a família e a sociedade em geral.

Toda paisagem é um produto da cultura e uma das condições nessa totalidade com que esta envolve o homem. Diante dos olhos, guardada na memória afetiva, idealizada pela saudade, a paisagem é a conversão da natureza em sentimentos. É uma perspectiva, um modo de ver, a escolha do objeto, o mundo habitado pela sensibilidade em sua aparência humanizadora. A apa- 
rência torna-se essência. Nessa linha, a paisagem é a natureza incorporada na alma e na cultura. Aí se tem a experiência estética, uma vez que é pela paisagem que a natureza atrai sobre sua forma a contemplação expressa a significação sensível. A paisagem é a natureza como cenário da cultura (LOUREIRO, 2002, p. 141)

Nesse contexto, há uma experiência estética representada fruto de um processo de identificação e construção de significados e que proporciona espaço para que outras experiências estéticas de identificação possam acontecer. Essas experiências podem acontecer por meio da intervenção pedagógica. Porém, antes de adentrarmos na discussão do método, abordaremos a noção de experiência estética e como ela pode contribuir para um processo de construção da identidade regional do sujeito surdo.

Quando nos referimos ao termo experiência estética, estamos entendendo a relação leitor/texto como uma relação de transformação, criação e desenvolvimento de novos sentidos e significados, assim como fortalecimento de valores de um determinado grupo linguístico. Nesse sentido, precisamos esclarecer que a experiência estética com a literatura se distancia da concepção de um contato entre leitor/texto, que é determinada estritamente pela fruição ou fins pedagógicos; todavia ela se caracteriza por apresentar uma função existencial e cultural no leitor, tendo um lugar próprio e bem específico no contato com uma obra.

A literatura deve, portanto, ser lida e estudada porque oferece um meio alguns dirão até mesmo o único - de preservar e transmitir a experiência dos outros, aqueles que estão distantes de nós no espaço e no tempo, ou que diferem de nós por suas condições de vida. Ela nos torna sensíveis ao fato de que os outros são muito diversos e que seus valores se distanciam dos nossos. (COMPAGNON, 2012, p. 47).

É importante dar a conhecer as obras para os surdos em fase de escolarização, para que possam pensar sobre si mesmos e o espaço em que vivem, bem como transformar para melhor suas práticas. Para Compagnon (2012, p. 50), “a literatura nos liberta de nossas maneiras convencionais de pensar a vida - a nossa e a dos outros".

Conforme Compagnon (2012, p. 54), "A literatura nos oferece a formação de si mesmo e o caminho em direção ao outro". Nesse sentido, a experiência estética com a literatura surda é um caminho ao encontro de si mesmo e cons- 
trução da sua própria identidade, assim como fortalecimento do sentimento de pertencimento e dos valores linguístico-culturais do povo surdo. Porém o aluno surdo, não raras vezes, somente tem acesso a esse tipo de produção na escola. Portanto cabe ao professor mediar esse contato e proporcionar momentos de experiência com a literatura.

\section{A INTERVENÇÃO LITERÁRIA NA ESCOLA: ESTRATÉGIA DE FORMAÇÃO CULTURAL DO POVO SURDO}

Nas narrativas regionais apresentadas nas figuras 1, 2 e 3, encontramos personagens surdos, utentes da Libras. Os mitos regionais são adaptados culturalmente, sem modificar o enredo geral das histórias. Nessas adaptações, passam a ser inseridos valores linguístico-culturais do povo surdo, desde o uso da língua, até mesmo o evidenciamento de alguns comportamentos culturais, tais qual o uso da expressão "eu te amo", como pode ser observado na figura 3, nos sinais com as mãos da personagem curupira e de outros animais. Essa expressão "eu te amo" é sinônimo de felicidade e revela o sentimento de pertencimento a um determinado grupo cultural. Sem dúvida, nessas narrativas, a língua constitui um instrumento fundante de marcação do pertencimento e dos valores específicos dos surdos. Com isso, podemos considerar que "a linguagem é um instrumento psicológico que media o pensamento em seu estágio inicial (como estágio inicial do pensamento ele quis dizer atividade prática). Como resultado de tal mediação verbal, o pensamento se desenvolve" (LEONTIEV, 1989, p. 25).

$\mathrm{Na}$ literatura surda, as personagens surdas evidenciam o valor da língua para os surdos, um valor internalizado, e com isso é disparado um instrumento cognitivo que, por meio do trabalho da mediação, favorece o desenvolvimento dos valores e da identidade do sujeito surdo. Conforme Leontiev (1989),

A linguagem egocêntrica é originalmente social. Ela não desaparece, mas se torna linguem interna. É internalizada. É o meio mais importante do pensamento que nasce na atividade externa, objetiva da criança. O pensamento verbal se desenvolve na medida em que a atividade é internalizada. (LEONTIEV, 1989, p. 25).

A escola é o espaço de contato privilegiado - e o primeiro - dos surdos com essas narrativas, um espaço de aprendizagem dos valores que constituem a cultura dos surdos, formando o ethos desse grupo cultural. Dessa forma, 
[...] a aprendizagem "motiva e desencadeia para a vida toda uma série de funções que se encontravam em fase de amadurecimento e na zona de desenvolvimento imediato [proximal - M. S.] Assim, a zona de desenvolvimento proximal caracteriza a diferença entre o que a criança é capaz por si mesmo e o que pode se tornar capaz com a ajuda de um professor. (LEONTIEV, 1989, p. 31).

A história tem participação nesse processo, mediada por signos que vão constituindo sentidos e significados ao longo do processo de aprendizagem. A história da educação dos surdos é marcada pela luta para que a Libras fosse reconhecida e o surdo compreendido em sua diferença. A escola é um espaço de descoberta de si e de valorização da sua diferença.

Aprender, conhecer e difundir a Libras é uma marcação dessas narrativas e o espaço em que isso é representado se liga aos elementos que compõem o ambiente amazônico. Há, portanto, na base da literatura surda regional, elementos histórico-culturais, ou seja, elementos que foram internalizados ao longo da história que não são somente individuais nem somente coletivos. Dessa forma, consideramos que as narrativas adaptadas culturalmente da literatura surda amazônica são representações de um processo de internalização, em que elementos internos e externos foram significados e ressignificados, ou seja, dialetizados; e, ao constituírem uma narrativa, podem servir de instrumento para colaborar no desenvolvimento de valores linguístico-culturais específicos dos surdos. A literatura é uma forma de signo que contribui no processo de internalização, mas precisa ser mediada.

Para Leontiev (1989), "uma função mental superior se desenvolve com base em uma função elementar que se torna mediada por signos no processo de internalização. Internalização é a lei fundamental do desenvolvimento para as funções mentais na ontogênese e filogênese" (LEONTIEV, 1989, p. 32). Esse processo tem o impacto dos elementos culturais e históricos construídos e internalizados pelo grupo do qual o sujeito surdo participa.

No processo mediador, segundo Vigotski (1969), a língua e a escola são instrumentos artificiais para o desenvolvimento do sujeito. Esses instrumentos são também mediadores da aprendizagem.

Na esteira de Vigotski (1969), Lenoir (1996), afirma que a mediação é fundamental no processo de aprendizagem, pois, nessa relação com o outro, o 
sujeito é interpelado a desenvolver sua criatividade, autonomia e posicionar-se diante de si e da sociedade, por isso dizer que o sujeito mediador é um ser essencialmente da práxis.

Segundo Lenoir (1996), o educador tem uma função transformadora no processo mediador, pois tem a possibilidade de fornecer para seus alunos um espaço propício para a aprendizagem, a criatividade e o exercício da reflexão de si mesmo e do outro.

O professor e a escola são mediadores externos que propiciam o contato primeiro com a literatura surda, para que o aluno possa, com seus recursos cognitivos, mediar internamente os processos internos, a partir de seus valores linguístico-culturais, desenvolvendo e fortalecendo valores. Para Lenoir (1996), trata-se, portanto, de um processo dialético, em que os instrumentos internos são sintetizados e ressignificados com os instrumentos mediadores externos.

Para Lenoir (1996), a mediação é um processo simbólico. Dessa forma, o conhecimento do objeto não significa apropriação do objeto, mas dispara operações internas, construções de sentidos e novos significados, desenvolvendo valores e o processo interno do sujeito. Assim, o processo mediador também pode ser considerado, segundo o autor, como regulador da formação de um determinado grupo cultural; por isso, ele afirma que a mediação constitui também um processo de intervenção.

O conceito de mediação e intervenção, portanto, têm uma aproximação e se constituem como sinônimos no processo de aprendizagem.

Segundo Lenoir (2009), a intervenção é uma ação interativa entre professor e aluno, tem como principal objetivo apresentar uma nova prática para um contexto específico de aula, a fim de minimizar uma problemática, criando condições adequadas de aprendizagem.

A língua nesse processo de intervenção representa um instrumento e também um elemento mediador; com isso, queremos reforçar que, ao realizar uma intervenção com a literatura surda amazônica, é importante que o interventor e/ou mediador a realize em Libras, respeitando o contexto linguístico dos aprendizes.

No caso dos surdos que vivem na região Amazônia Legal, o contato com a literatura produzida pela comunidade surda da região, por meio da intervenção educativa, representa uma chave no processo de formação de seus valores 
Literatura surda na região amazônica: o ambiente educacional como espaço da construção da identidade a partir da experiência estética

linguístico-culturais, e o professor e a escola são fundamentais para que esse processo aconteça. Os valores culturais que fazem parte desse grupo específico de surdos não se apresentam apenas com o uso da Libras, mas, de acordo com a literatura surda produzida na região amazônica, evidenciam a relação com a natureza, um sujeito que busca, enquanto surdo, integrar-se com o ambiente da região. Isso pode ser observado na representação dos espaços que o cercam: as etnias indígenas, os animais, os frutos, a floresta, o rio, o barco, as cores vivas e harmônicas, um sujeito integrado com a natureza.

A formação da identidade do surdo presente na região amazônica tem uma especificidade em suas produções literárias e deve ser levada em consideração na formação desse aluno. A intervenção educativa, por meio da experiência estética, é um caminho estratégico que interpela o surdo a posicionar-se enquanto sujeito, pensar sobre si mesmo e seus valores linguístico-culturais. Portanto o processo de identificação com as produções de seu próprio grupo cultural é fundamental para o desenvolvimento de sua identidade enquanto sujeito surdo.

A mediação, na forma da metodologia da intervenção educativa, é uma proposta. Para tanto, é preciso que ocorra o planejamento por parte do professor, considerando os aspectos linguísticos da turma, e o conhecimento tanto em Libras (caso tenha versão em Libras) quanto da língua portuguesa, para que o professor organize a intervenção de maneira a oferecer tempo e formas de conhecer o texto. Também pode ser explorada a leitura visual da obra. É o caso das narrativas apresentadas na figura 2 e 3. Enfim, a metodologia da intervenção educativa é um caminho possível, que contribui no processo de formação da identidade do sujeito surdo; em nosso caso, apresentamos a literatura surda da região amazônica como instrumento para a formação da sua identidade.

\section{CONSIDERAÇÕES}

A literatura surda da região amazônica proporciona uma formação tanto no sentido regional quanto no sentido dos valores linguístico-culturais do povo surdo. Não há como separar esses dois universos de aprendizagem para os surdos dessa região.

Os instrumentos externos (escola, literatura, cultura, história) são articulados por meio de um processo mediador disparado pelo professor, que também tem 
o papel de interventor. Assim, os instrumentos externos podem ser dialetizados pelo aluno com seus instrumentos internos, a fim de desenvolver valores e os internalizar, proporcionando uma formação específica para o surdo da região amazônica.

A metodologia da intervenção pedagógica constitui um instrumento para proporcionar condições para uma experiência estética com a literatura surda, fortalecendo os valores linguístico-culturais dos surdos e o respeito para com as diferenças.

Com isso, podemos aferir que a experiência estética com a literatura surda produzida na região proporciona a práxis formadora e transformadora de práticas sociais, em que as diferenças devem ser respeitadas e consideradas na formação tanto de sujeitos surdos como também de ouvintes que constituem parte desse universo escolar. Assim, podemos afirmar, como Compagnon (2012), que a literatura nos torna pessoas melhores!

\section{REFERÊNCIAS}

COMPAGNON, Antoine. Literatura para quê? Tradução de Laura Taddei Brandini. Belo Horizonte: UFMG, 2012.

ESPÍNDOLA, Amarildo João; SILVA, Elielza Reis da; PISSINATTI, Larissa Gotti. Curupira surdo. Porto Velho, RO: AICSA, 2016.

HOLCOMB, Thomas K. Introduction to American deaf culture. New York: Oxford, 2013.

KARNOPP, Lodenir Becker. Literatura surda. ETD - Educação Temática Digital, Campinas, SP, v. 7, n. 2, p. 98-109, jun. 2006. Disponível em: https://periodicos.sbu.unicamp.br/ojs/ index.php/etd/article/view/795/810. Acesso em: 20 mar. 2019.

LENOIR, Yves. L'intervention éducative, un construit théorique pour analyser les pratiques d'enseignement. Nouveaux Cahiers de la Recherche em Éducation, [S.I.], v. 12, n. 1, p. 9-29, 2009. Disponível em: https://www.erudit.org/fr/revues/ncre/2009-v12-n1ncre0747/1017474ar.pdf. Acesso em: 11 jan. 2017.

LENOIR, Yves. Médiation cognitive et médiation didactique. In: RAISKY, Claude; CAILLOT, Michel (Ed.). Au-dela des didactiques, le didactique. Débats autour de concepts fédérateurs. Bruxelles: De Boeck Université, 1996. p. 223-51. 
Literatura surda na região amazônica: o ambiente educacional como espaço da construção da identidade a partir da experiência estética

LEONTIEV, Alexei Nikolaevich. Sobre o desenvolvimento criativo de Vigotski. Tradução de Marcelo José de Souza e Silva. 1989. Disponível em: https://www.marxists.org/portugues/ leontiev/1979/01/vigotski.htm. Acesso em: 18 mar. 2019.

LOUREIRO, João Paes de Jesus. Elementos de estética. 3. ed. Belém, PA: EDUFA, 2002.

MONTEIRO, Tatyana. Negrinho e Solimões. Ilustração de Sérgio Barbosa Lopes Júnior. Manaus: BK Editora, 2014.

MOURÃO, Cláudio Henrique Nunes. Literatura surda: produções culturais dos surdos em Língua de Sinais. 2011. Dissertação (Mestrado em Educação) - Universidade Federal do Rio Grande do Sul, Porto Alegre, 2011. Disponível em: http://www.lume.ufrgs.br/ handle/10183/32311. Acesso em: 20 mar. 2019

SALES, Taísa Aparecida Carvalho (org). Onze histórias e um segredo: desvendando as lendas amazônicas. Ilustrações de Edilson Morais da Silva. Manaus: Damir Pacheco Souza, 2016.

STROBEL, Karin. As imagens do outro sobre a cultura surda. 3. edição. Florianópolis: Editora da UFSC, 2013.

VIGOTSKI, Lev Semyonovich. Manuscrito de 1929. Tradução de Alexandra Marenitch. Educação e Sociedade, Campinas, SP, ano XXI, n. 71, jul. 2000. Disponível em: https:// www.scielo.br/pdf/es/v21n71/a02v2171.pdf. Acesso em: 18 mar. 2019.

VIGOTSKI, Lev Semyonovich. Psicologia. Tradução de Florencio Villa Landa. 3. ed. México: Editorial Grijalbo, 1969.

WOORDWARD, Kathryn. Identidade e diferença: uma introdução teórica e conceitual. In: SILVA, Tomaz Tadeu (Org.); HALL, Stuart; WOODWARD, Kathryn. Identidade e diferença-a perspectiva dos estudos culturais. 12. ed. Petrópolis, RJ: Vozes, 2012. p. 7-72.

\section{Sobre as autoras:}

Nerli Nonato Ribeiro Mori: Doutora em Psicologia Escolar e do Desenvolvimento Humano pela Universidade de São Paulo (USP). Mestre em Psicologia da Educação pela Pontifícia Universidade Católica do Paraná (PUC-PR). Professora titular do Departamento de Teoria e Prática da Educação e do Programa de PósGraduação em Educação da Universidade Estadual de Maringá (UEM). E-mail: nnrmori@uem.br, Orcid: http://orcid.org/0000-0002-6798-5225 
Larissa Gotti Pissinatti: Mestre em Estudos Literários pela Universidade Federal de Rondônia (UNIR). Professora assistente do Departamento de Libras da UNIR. E-mail: larissa.pissinatti@unir.br, Orcid: http://orcid.org/0000-0002-7964-7063

Recebido em 27 de março de 2019.

Aprovado em 20 de maio de 2020. 